\title{
A DIMENSÃO DO CURSO DE GESTÃO DE ARQUIVO NA UNIVERSIDADE FEDERAL DO MARANHÃO
}

\author{
Maria Mary Ferreira \\ Aldinar Martins Bottentuit \\ Georgete Lopes Freitas
}

\begin{abstract}
Resumo
Discussão acerca do Curso de Especialização em Gestão de Arquivo, promovido pela Universidade Federal do Maranhão (UFMA), como resposta à crescente demanda e interesse dos(as) bibliotecários(as) e historiadores(as) que atuam nos lugares de memória de São Luís, advindos (as) de instituições federais, estaduais e municipais, tais como arquivos públicos, além de arquivos de igrejas, de associações, hospitalares, universitários, jurídicos, familiares, pessoais, empresariais, centros de documentação que compõem o cenário arquivístico de São Luís. Este curso busca contribuir para a formação de profissionais no campo da Arquivologia, uma vez que as Instituições de Ensino Superior (IES) maranhenses ainda não oferecem cursos de graduação neste campo. A proposta é formar gestores(as) críticos(as) e reflexivos(as) sobre as suas práticas profissionais e não somente executores(as) burocráti$\cos$ (as) de atividades arquivísticas, com capacidade de pensar políticas de gestão de docu-
\end{abstract}

\section{INTRODUÇÃO}

O campo da Arquivologia tem se beneficiado nos últimos quinze anos de pesquisas e novos conhecimentos que comportam teorias e princípios para pensar criticamente sobre a sua epistemologia. Durante muito tempo, ficamos mais volta- mentos públicos e privados, com a perspectiva de contribuir para recompor a memória dos/as maranhenses em diferentes contextos. Esta orientação pôde ser confirmada parcialmente quando se evidenciou o interesse por parte dos(as) discentes, em eleger como objeto de investigação a realidade que vivenciam no seu local de atuação, numa perspectiva de compreender e transformar as suas práticas, alicerçada também num referencial teóricometodológico da Arquivologia e demais campos interdisciplinares.

\section{Palavras-chave}

Formação do(a) arquivista; Curso de Gestão de Arquivo; Universidade Federal do Maranhão

dos para uma prática manualística do saber-fazer, às vezes acrítico, sem atentarmos para questões de fundo que perpassaram e perpassam as nossas práticas.

Da Arquivologia clássica, com seus princípios norteadores e hoje, com o projeto pós-custodial, com a presença das tecnologias de informação no interior das insti- 
tuições, outros são os desafios que se apresentam de forma inexorável para os estudiosos desse campo, tais como a gestão documental, a transparência administrativa em tempos de governança eletrônica, preservação dos documentos eletrônicos, registros virtuais e transitórios, banco de dados multidirecionados, as novas competências para o profissional arquivista e sua relação com outros profissionais da informação. A esses desafios, soma-se a necessidade de trabalhar a transversalidade de conteúdos, dada a urgência de garantir o acesso e o direito à informação.

O Curso de Especialização em Gestão de Arquivo foi criado em 2003, pelo Departamento de Biblioteconomia da UFMA, em razão da demanda do mercado e da carência de profissionais para o desenvolvimento de atividades em arquivos. Os indicadores que nortearam a sua fundamentação demonstraram a inexistência de políticas de arquivo no Estado, a falta de profissionais com qualificação específica e a má conservação dos acervos arquivísticos, o que ocasionou e tem ocasionado perdas imensuráveis de documentos importantes para a história e memória do Maranhão. Por outro lado, estudos realizados por professores do Departamento de Biblioteconomia apresentam um interesse crescente pela Arquivologia, sendo um dos campos de maior freqüência de projetos de monografia, como corrobora o estudo de Ferreira (2001).
Tais demandas fortaleceram a idéia de se criar uma outra habilitação, a Arquivologia, como já previsto no Projeto Político Pedagógico da UFMA e como acontece na maioria dos Departamentos de Ciência da Informação das universidades brasileiras, que além do Curso de Biblioteconomia oferecem a graduação em Arquivologia (UEL, UFBA, UFES, UFF, UFMG, UFRGS, UNIRIO, UnB, UNESP-Marilia) ${ }^{1}$. Esse projeto em andamento no Departamento foi um dos argumentos que favoreceu a implantação imediata de um curso de Especialização, a fim de suprir imediatamente essa necessidade, já que a criação de curso de graduação implicava custos, estrutura pedagógica e física, entre outros ajustes não solucionáveis em curto prazo.

Outro fator que acelerou a implantação do curso está relacionado com o número de graduandos(as) nos campos de Biblioteconomia e História, que mantêm afinidade com a Arquivologia. Graduam-se, em média, 25 alunos(as) em Biblioteconomia e 60 alunos(as) de História por ano nas duas universidades públicas do Estado. Grande parte demonstrou interesse pela área, o que fortaleceu a idéia de qualificação de profissionais para atuar nos ar-

\footnotetext{
${ }^{1}$ Universidade Estadual de Londrina - UEL, Universidade Federal da Bahia - UFBA, Universidade Federal do Espírito Santo - UFES, Universidade Federal Fluminense - UFF, Universidade Federal de Minas Gerais - UFMG, Universidade Federal do Rio Grande do Sul - UFRGS, Universidade Federal do Estado do Rio de Janeiro - UNIRIO, Universidade de Brasília - UnB, Universidade Estadual Paulista UNESP-Marília.
} 
quivos, além de possibilitar a educação continuada daqueles bibliotecários(as) e historiadores(as), atuantes nos diversos lugares de memória de São Luís e que devem prestar os seus serviços aos/as cidadãos(ãs), com qualidade.

Diante do apresentado é que se coloca este trabalho, cujo desenvolvimento serve de referência para compreendermos as nossas práticas, quer seja na mediação como docente em disciplina, no acompanhamento de estágio curricular, no desenvolvimento da atividade de orientação de monografia ou ainda na avaliação dos(as) profissionais que têm sido colocados(as) nos arquivos em constante sintonia com o trabalho que o Curso desenvolve.

$\mathrm{Na}$ construção deste estudo buscamos uma abordagem mais transversal e interdisciplinar, dada a particularidade do curso e os sujeitos envolvidos na formação. A construção teórico-metodológica privilegiou as abordagens de autores(as) e pesquisadores(as) como Heloísa Bellotto, Carol Couture, Jean-Yves Rousseau, Armando Malheiro da Silva, Maria Odyla Fonseca, entre outros(as), que vêm contribuindo sistematicamente com o campo da Arquivologia no Brasil e, internacionalmente, disseminando suas idéias e pesquisas.

$\mathrm{Na}$ abordagem, foi levada em conta a complexidade do modelo da Sociedade da Informação na qual estamos inseridos, mas sem perder de vista o fato de estarmos situados em uma região muito pobre do
Brasil, a Nordeste, detentora de grandes índices de exclusão social, educacional e digital e que se ressente com a falta de políticas públicas no campo da Informação. Outra preocupação é o fato de São Luís ser considerada, desde 1997, Patrimônio Cultural da Humanidade e isto se deve ao seu conjunto de documentos e monumentos, o que fortaleceu a idéia de pensar e estimular uma política pública de recuperação, registro, preservação e conservação de documento, garantindo a permanência da memória do nosso patrimônio documental e arquitetônico.

Nesse contexto, para responder a algumas questões aqui propostas, este texto foi assim estruturado: no primeiro momento, discorremos sobre os desdobramentos epistemológicos que influenciaram a estrutura curricular do Curso; depois, apresentamos os temas das monografias defendidas e discutimos como as mesmas buscaram responder a alguns problemas que estão presentes nos arquivos de São Luís.

\section{CURSO GESTÃO DE ARQUIVO: al- guns resultados}

O princípio que norteou a criação deste curso foi a formação de profissionais qualificados e com visão política, a fim de contribuir para a formação de gestores críticos e reflexivos sobre as suas práticas e com capacidade de produzir conhecimento capaz de intervir na formulação de políticas 
de gestão de arquivo no Estado.

Com base nesse pressuposto e por acreditar que cabe à universidade o compromisso com a dimensão investigativa, o Curso de Gestão em Arquivo tem buscado fomentar em seus discentes a produção de conhecimentos que contribuam para o crescimento e amadurecimento do campo da Arquivologia. Esse pensamento é corroborado pelos pesquisadores Rousseau e Couture (1988, p.257), quando expressam que essas instituições (as universidades) "[...] são as únicas a dispor de experiência, dos instrumentos e da credibilidade social para o fazerem".

Nesse particular, a Arquivologia, como todo campo do conhecimento, deve ampliar as suas fronteiras com outros campos interdisciplinares, promover novos embates teóricos, novas pesquisas, mas sem perder de vista o que Boaventura Santos (2003) chama de paradigma emergente, ou melhor expressando, "o paradigma de um conhecimento prudente para uma vida decente", onde a ciência, a geração de conhecimento deve estar alicerçada numa prática social comprometida com o bem-estar da humanidade. Dentro desta perspectiva, algumas questões permearam a feitura do curso: qual profissional queremos formar? Com quais conhecimentos? Para quê?

Nesse espírito, buscamos estruturar o curso com as disciplinas assim constituídas: fundamentos teóricos, metodológicos e seminários temáticos, que são definidos considerando a atualidade do conteúdo e interesse profissional dos(as) discentes. As disciplinas que compuseram o quadro curricular são: metodologia do ensino superior; fundamentos teóricos de arquivologia; preservação e conservação de documentos em diferentes suportes; processamento de informação arquivística; métodos e técnicas de pesquisa histórica; metodologia da pesquisa em arquivologia, fundamentos de paleografia e diplomática: gestão em arquivos permanentes, planejamento e dinamização de serviço de informação arquivística e os seminários, como digitalização e microfilmagem de acervo e estrutura do trabalho científico. (UFMA, 2006)

As disciplinas de fundamentação teórica possibilitaram-nos um espaço de debate acerca das teorias e conceitos sobre a Arquivologia na atualidade, como Rousseau e Couture (1998, p. 284), que defendem a arquivística integrada e a

consideram como uma disciplina que rege a gestão da informação orgânica (arquivos). Pode assumir três formas: uma forma exclusivamente administrativa (records management), cuja principal preocupação é o valor primário do documento; uma forma tradicional, que ressalta unicamente o valor secundário do documento; uma forma nova, integrada e englobante, que tem como objetivo ocupar-se simultaneamente do valor primário e do valor secundário do documento.

Silva e colaboradores (1998, p.214) que a expressa como uma

Ciência de informação social, que 
estuda os arquivos como sistemas de informação, quer na sua estruturação interna e na dinâmica própria, quer na interação com os outros sistemas correlativos que coexistem no contexto envolvente.

São conceitos que remetem a uma visão de como o campo é tratado na atualidade, por esses autores. Pensamos que é também relevante construir uma discussão acerca da visão tradicional de arquivo e mostrar como a concepção sobre o mesmo se ampliou em função de uma perspectiva mais social e científica, considerado como lugar de memória, de cultura e de pesquisa.

Neste sentido, as disciplinas foram pensadas e planejadas com vistas a fundamentar o trabalho dos(as) arquivistas, e, ao mesmo tempo, possibilitar a reflexão sobre essas práticas, considerando que muitos(as) advêm, ora do curso de Biblioteconomia ora da História, ficando lacunar no que se refere aos conteúdos da Arquivologia. Também foi necessário contemplar conteúdos mais especializados como preservação, conservação preventiva, digitalização de acervos, que pelo próprio suporte dos documentos, em sua maioria, papel, exigem acompanhamento, além dos novos que se inserem neste conjunto, como os eletrônicos. A este respeito, Bellotto (2004, p.299) lembra que "[...] os novos suportes documentais com os quais terá de lidar exigem conhecimento, competências, métodos e meios de produção, utilização e conservação física especiais."
Algumas disciplinas, como Processamento de Informação Arquivística, Métodos e Técnicas de Pesquisa Histórica, Gestão de Arquivo Permanente, vêm ao encontro de uma necessidade premente na maioria dos arquivos públicos brasileiros, como a falta de instrumentos de pesquisa eficazes que orientem os pesquisadores na busca, identificação e recuperação de informações que estão potenciais nos acervos documentais.

A disciplina Metodologia da Pesquisa em Arquivologia e o seminário Estrutura do Trabalho Científico deram subsídios aos(às) discentes para caminharem na construção de suas pesquisas. Desse modo, a elaboração do trabalho monográfico e todo o processo de pesquisa que ele comporta possibilitaram aos(às) mesmos(as) refletirem mais profundamente sobre a realidade que vivenciam, buscando respostas e/ou intervindo positivamente para a meIhoria da prestação de serviços à comunidade usuária.

Por outro lado, não podemos perder de vista a necessidade de uma formação qualitativa e crítica do(a) arquivista, considerando que o seu trabalho envolve a gestão da informação arquivística e todos os produtos advindos daí, e que muitos dependem desse trabalho para acessá-la nos conjuntos documentais, uma vez que, o(a) arquivista é o(a) mediador(a) entre essa informação registrada/materializada e o(a) usuário(a). 
O Curso de Especialização em Gestão de Arquivos iniciou sua primeira turma com 50 alunos(as), dentre os quais 39 defenderam suas monografias. Ao avaliar os resultados e a repercussão do curso no Estado, observamos que o número de alunos(as) inscritos(as) e os resultados alcançados foram satisfatórios. Isso é mensurado a partir da demanda obtida pelo curso e os produtos finais analisados, considerando o número de monografias defendidas dentro dos prazos previstos e ao apresentarem estudos que apontam reflexões de cunho teórico-metodológico que em muito contribuem para melhorar o desempenho das instituições arquivísticas no Estado. Apresentamos em apêndice, um quadro com as autorias, os títulos os respectivos resumos das monografias aqui citadas e comentadas para um melhor entendimento do conteúdo das mesmas.

Os trabalhos apresentados tratam de problemáticas amplamente discutidas no conteúdo programático do curso e que remetem a uma preocupação que, de certa maneira, tem sintonia com problemas vivenciados pelos arquivos brasileiros e de outros países: a gestão dos documentos, que inclui a identificação dos fundos documentais das organizações, política de preservação e conservação preventiva dos documentos; perfil profissional e mercado de trabalho; a memória dos arquivos e a reconstituição da história e da cidadania dos (as) maranhenses.
Além desses temas, o curso traz preocupações para a sociedade no que se refere à necessidade de pensar e instituir políticas para preservação e guarda dos acervos fotográficos e tema bastante pertinente para a Cidade de São Luís, em virtude de sua elevação à Patrimônio da Humanidade em 1997, pelo seu rico acervo arquitetônico e colonial português dos séculos XVIII e XIX.

Tal foco constituiu-se objeto de estudo de Márcia Pereira e Vitória Carvalho, ao pesquisar o arquivo fotográfico do Instituto do Patrimônio Histórico e Artístico Nacional (IPHAN), demonstrando a necessidade de se manterem políticas de preservação no Estado para os acervos fotográficos, imprescindíveis para a reconstituição do patrimônio cultural do Maranhão. A fotografia também se constituiu objeto de estudo de mais dois trabalhos de autoria de Ana Maria Ferreira e Claudete Brandão e Alessandra Rocha e Márcia Silva. Isto demonstra a preocupação com outros tipos de documentos, uma vez que lidar com o documento imagético exige conhecimento técnico.

Dos variados temas abordados nos estudos, ressaltamos ainda aqueles relacionados com gestão de documentos hospitalares que traz a público a necessidade de repensar o direito do(a) paciente de acesso a informações anteriormente consideradas de natureza privada, já que poucos tinham acesso a seus prontuários mé- 
dicos. No estudo de Ana Luiza Magalhães, Lourdes Fernandes e Antonio Silva, os autores demonstram o quanto é importante organizar e disponibilizar essas informações clínicas como perspectiva de direito, de cidadania.

Nesse mesmo caminho, pode ser apontado o estudo de José Ribamar Nojosa e Valdelina Frazão, quando propuseram uma organização para o acervo do Tribunal de Contas do Estado do Maranhão, como forma de implementar uma política de gestão de documentos e conseqüentemente democratizar o acesso às informações antes consideradas sigilosas. Ainda no contexto de arquivo jurídico, também podemos citar o Programa de Gestão Documental na Justiça do Trabalho do Maranhão, tema da monografia de Raimunda Teixeira e Cláudia Pecegueiro.

Esses estudos, de certa maneira, respondem a uma necessidade cada vez mais presente na sociedade, que exige serviços de qualidade e busca formas de se apropriar de direitos antes negados pelo Estado. Hoje, podemos até mesmo afirmar que a principal justificativa para a existência dos arquivos para a maioria dos usuários e para o público em geral repousa no fato de os arquivos serem capazes de oferecer aos cidadãos um senso de identidade, de história, de cultura e de memória pessoal e coletiva.(COOK, 1997 apud FONSECA, 2005, p.61).

Percebemos, ainda, nos resultados dos estudos, uma preocupação em pensar o campo da Arquivologia sob o olhar de quem está direta e indiretamente ligado à área, seja na condição de técnico, seja na condição de pesquisador que busca os arquivos como fonte de pesquisa. Esse dado foi tema do estudo de Elisabeth Berniz e Márcio Henrique Almeida, que estudaram o perfil dos(as) arquivistas do Estado, analisando como esses e essas profissionais construíram suas práticas. Outro estudo que também reflete a construção da arquivística como campo de estudo no Maranhão é o de Ivesângela Ribeiro e Maria Lúcia Fonseca que analisaram os parâmetros que fundamentaram a criação do Curso de Gestão de Arquivo na Universidade Federal do Maranhão.

Houve, ainda, o interesse de pesquisas por parte dos discentes de alguns arquivos especializados e/ou privados como os da Igreja de São Luis, de associações comercias, banco, companhia energética, correios, de cemitério, cartório de comarca, onde as alunas Clores Silva, Rosenilde Costa; Surama Freitas; Maria José Castro e Tânia Pavão; Carmencita Santos e Marileide Araújo; Edilene Campos e Maria do Carmo Sousa; Lucia Silva e Rosana Sousa, buscaram evidenciar as formas pelas quais esses arquivos estão sendo organizados e se essa organização segue as orientações teórico-metodológicas da literatura arquivística.

O trabalho que tratou da Coleção Mu- 
seológica de Padre João Mohana, de autoria de Moisés Silva e Altiva Paixão e do Museu Histórico e Artístico do Maranhão de Geysa Carvalho e Sylvania Sá, e do acervo de livros da Biblioteca Central da UFMA de Maria de Fátima Pinheiro e Rosanna Bezerra, também buscaram conhecer e avaliar as condições físicas da coleção e, a partir do diagnóstico, sugerir mudanças e/ou intervir no tratamento das mesmas.

No que se refere à atuação no mundo do trabalho, a monografia de Elcinete Coutinho, intitulada Ações Empreendedoras no Campo da Arquivística no Maranhão, traz uma contribuição no sentido de mapear algumas atitudes empreendedora que o profissional deve ter ou adquirir, uma vez que ao lado das tradicionais instituições empregadoras governamentais públicas e outras de caráter privado, há um potencial no mercado maranhense de prestação de serviços, com a organização de arquivos pessoais, familiares, empresariais, entre outros, além da terceirização de serviços.

Outros olhares tiveram como destino o Arquivo Público do Estado (APEM), instituição que pela sua própria natureza recoIhe, trata, preserva, conserva, divulga e disponibiliza a documentação gerada cotidianamente pelos diversos organismos públicos da administração direta e indireta e que há muitos anos denuncia a falta de política e gestão sistêmica de recebimento de documentos. Aliás, essa situação de ingerência da documentação pública governamental, é freqüente no Estado brasileiro, e já bem evidenciada por Jardim (1999, p.197) quando expressa que "a opacidade informacional não é uma questão de governo. Trata-se de um atributo do Estado e um tributo pago pela sociedade civil". Portanto, a falta de organização e sistematização dos arquivos públicos, assim como dos privados, fortalece esta situação, ou seja, a da não transparência administrativa.

Assim sendo, monografias como de Helena Espínola e Francisca Andrade mostram aspectos do potencial de estudos que podem ser desenvolvidos, considerando o arquivo como lugar de memória - conceito muito bem cunhado pelo pesquisador Pierre Nora - e lugar de pesquisa, para que o(a) cidadão(ã) visite e conheça o seu acervo. A este respeito, concordamos com Belloto (2004, p. 278) quando expressa que "o sentido de divulgar deve estar voltado não só para o historiador, mas também para o grande público".

A tecnologia da digitalização também foi contemplada com o trabalho intitulado "Uma proposta de digitalização dos projetos da Secretaria de Estado de Justiça e Cidadania (SEJUSC)", de Albertina Conceição e Nadia Alves. Sugerem as autoras, entre outras recomendações, que a instituição deve adotar a digitalização para a conservação do material em suporte papel, uma vez que o constante manuseio com- 
promete ao longo dos anos a qualidade e integridade física desse material, dando maior possibilidade de acesso aos interessados na forma digital.

Faz-se necessária, pois, uma gestão e organização dos arquivos que garanta ao cidadão e à cidadã o direito à informação, de forma transparente. Para tanto, os/as arquivistas devem construir suas práticas no sentido de fortalecer tais direitos, condição para uma sociedade democrática.

\section{CONCLUSÃO}

De uma forma geral, o Curso retratou a realidade de uma área ainda pouco valorizada pelas políticas de cultura no Estado. E a ausência de políticas de informação tem favorecido o quadro de fragilidades em que muitas dessas instituições estão mergulhadas.

Por outro lado, os temas tratados nas monografias sinalizam para preocupação dos(as) alunos(as) com os problemas presentes em seus lugares de trabalho, buscando romper com uma forma empírica de atuar, e nesta perspectiva, o curso contribuiu significativamente para reflexão e conseqüente melhoria de suas práticas profissionais.

Nesse sentido, cabe à Universidade Federal do Maranhão fazer desses estudos um instrumento público para mudanças de postura e construção de novos paradigmas que venham modificar as estruturas orga- nizacionais com vistas à preservação dos acervos documentais, acesso e a formação de uma consciência crítica da importância dos mesmos para compreensão e resgate de nossa memória, de nossa história.

\section{REFERÊNCIAS}

FERREIRA, Maria Mary. A produção monográfica no Curso de Biblioteconomia da Universidade Federal do Maranhão: 19902000. Departamento de Biblioteconomia, 2001. $30 \mathrm{fl}$.

FONSECA, Maria Odila. Arquivologia e Ciência da Informação. Rio de Janeiro: FGV, 2005.

BELLOTTO, Heloísa Liberalli. Arquivos permanentes: tratamento documental. 2 ed. Rio de Janeiro: FGV, 2004.

SANTOS, Boaventura. Um discurso sobre as ciências. Porto: Afrontamento, 2003.

SILVA, Armando Malheiro da et al. Arquivística: teoria e prática de uma ciência da informação. Porto: Afrontamento, 2002. $174 \mathrm{p}$.

ROUSSEAU, Jean-Yves; COUTURE, Carol. Os fundamentos da disciplina arquivística. Lisboa: Dom Quixote, 1994.

UNIVERSIDADE FEDERAL DO MARANHÃO. Departamento de Biblioteconomia. Relatório de atividades do Curso de Especialização em Gestão de Arquivo. São Luis, 2006. 


\begin{abstract}
Maria Mary Ferreira
Mestre em Políticas Públicas (UFMA). Doutora em Sociologia (UNESP-Araraquara). Professora do Departamento de Biblioteconomia (UFMA) mmulher13@hotmail.com.br
\end{abstract}

Aldinar Martins Bottentuit Mestre em Ciência da Informação (Unb). Professora do Departamento de Biblioteconomia (UFMA) aldinarb@yahoo.com.br

Georgete Lopes Freitas Mestre em Biblioteconomia (PUC-Campinas). Professora do Departamento de Biblioteconomia (UFMA) georgete@elo.com.br

\section{Title}

The dimension of the Records Management Course at the Federal University of Maranhao

\footnotetext{
Abstract

Discuss the Specialization Course in Records Management of the Universidade Federal do Maranhão due to the increasing demand and interest of librarians and historians which work in places that maintain the São Luís' history. Those professionals come from federal, municipal and state institutions, such as National Archives. Besides, São Luís' archive panorama is also composed of churches, associations, hospitals, universities, law institutions, families, individuals and business archives. The Records Management course intends to contribute to the education development of archivists, once the universities in Maranhão still do not offer graduation courses related to Archive Science. The objective of this course is to prepare critical and reflective professionals, instead of archivists that perform only bureaucratic activities, as they have the duty of contributing on recovering maranhenses history in several contexts. This task was partially confirmed when the major interest of the students was attested: they elected as investigation object the reality within they cohabit in their workplace, based on a theorical and methodological reference of Archive Science and other interdisciplinary fields to comprehend and to change some work practices.
}

\section{Keywords}

Archive Professional's Education; Records Management course; Universidade Federal do Maranhão

\section{Título}

La Dimensión del Curso de Gestión de Archivo en la Universidade Federal de Maranhão

\section{Resumen}

Discusión sobre el Curso de Especialización en Gestión de Archivo, promovido por la Universidad Federal de Maranhão, como respuesta a la creciente demanda e interés de los/las bibliotecarios/as e historiadores/as, que actúan en sitios de memoria de São Luís, advindo de instituciones federales, estaduales y municipales, tales comos archivos públicos, además de archivos de iglesias, de asociaciones, hospitalarios, universitarios, jurídicos, familiares, personales, empresariales y centro de documentación que componen el escenario archivístico de São Luís. Este curso busca contribuir para la formación de profesionales en el campo de Archivología, una vez que las Instituciones de Enseñanza Superior (IES) de Maranhão todavía no ofrecen cursos de graduación en este campo. La propuesta es formar gestores/as críticos/as y reflexivos/as sobre sus prácticas profesionales y no sólo ejecutores/as burocráticos/as de actividades archivísticas, con capacidad en políticas de gestión de documentos públicos y privados con la perspectiva de contribuir para recomponer la memoria de los/las "maranhenses" en diferentes contextos. Esta orientación puede ser confirmada parcialmente cuando se evidenció el interés por parte de los alumnos en elegir como objeto de investigación la realidad que vivencían en su local de actuación, en una perspectiva de comprender y transformar sus prácticas, basada también en un referencial teórico-metodológico de Archivología, además de los campos interdisciplinares.

\section{Palabras Clave}

Formación del archivista; Curso de Gestión de Archivo; Universidade Federal de Maranhão. 
Recebido em: 24.04.2007

Aceito em: 24.07.2007

\section{APÊNDICE - QUADRO DA PRODUÇÃO DO CURSO DE ESPECIALIZAÇÃO EM GES- TAिO DE ARQUIVO - UFMA}

\begin{tabular}{|c|c|c|}
\hline AUTORAS/ES & $\begin{array}{c}\text { TÍTULO DAS } \\
\text { MONOGRAFIAS }\end{array}$ & CONTEÚDO ABORDADO \\
\hline $\begin{array}{l}\text { Albertina Silva } \\
\text { da Conceição; } \\
\text { Nadia Sebastia- } \\
\text { na Matos No- } \\
\text { gueira Alves. }\end{array}$ & $\begin{array}{l}\text { Arquivos e responsabilida- } \\
\text { de social: uma proposta de } \\
\text { digitalização dos projetos } \\
\text { da Secretaria de Estado de } \\
\text { Justiça e Cidadania - } \\
\text { SEJUSC. }\end{array}$ & $\begin{array}{l}\text { Trabalho que tem o propósito de auxiliar a Se- } \\
\text { cretaria de Estado de Justiça e Cidadania } \\
\text { (SEJUSC), guardiã de um acervo documental } \\
\text { de valor permanente, a utilizar os recursos das } \\
\text { novas tecnologias da informação, no sentido de } \\
\text { preservar o patrimônio documental e de demo- } \\
\text { cratizar o acesso ao público interessado. Objeti- } \\
\text { vou-se identificar o acervo de projetos do servi- } \\
\text { ço voluntário dispersos nas assessorias do ór- } \\
\text { gão em estudo, possibilitando a organização, } \\
\text { guarda, preservação e disponibilidade para o } \\
\text { meio digital. O trabalho visa estimular outras } \\
\text { instituições para que possam organizar seus } \\
\text { arquivos de forma digital e assim contribuir para } \\
\text { o desenvolvimento das ações sociais destina- } \\
\text { das a outras comunidades usuárias. }\end{array}$ \\
\hline $\begin{array}{l}\text { Alessandra Yle- } \\
\text { nia Oliveira Ro- } \\
\text { cha; Márcia Re- } \\
\text { gina Barreto } \\
\text { Silva. }\end{array}$ & $\begin{array}{l}\text { Acervo fotográfico de sinis- } \\
\text { tros da Empresa Taguatur: } \\
\text { uma proposta de organiza- } \\
\text { ção. }\end{array}$ & $\begin{array}{l}\text { Diretrizes para organização do acervo fotográfico } \\
\text { de sinistros (desastres, acidentes) da Empresa } \\
\text { Taguatur, desenvolvido a partir de um diagnósti- } \\
\text { co da situação real dos documentos. Na propos- } \\
\text { ta de organização são descritas as etapas, à luz } \\
\text { dos princípios norteadores da Arquivística. }\end{array}$ \\
\hline $\begin{array}{l}\text { Altiva Loureiro } \\
\text { Paixão; Moises } \\
\text { da Costa Silva. }\end{array}$ & $\begin{array}{l}\text { Coleção musicológica Pa- } \\
\text { dre João Mohana. }\end{array}$ & $\begin{array}{l}\text { Evolução do Arquivo Público do Estado do Ma- } \\
\text { ranhão - APEM, como instituição capaz de reco- } \\
\text { Iher, preservar e divulgar a documentação pro- } \\
\text { duzida e acumulada pelas administrações direta } \\
\text { e indireta do Estado. Dentre o seu acervo docu- } \\
\text { mental, destaca-se a coleção musicológica do } \\
\text { Padre João Mohana, parte integrante do acervo } \\
\text { do APEM. Apresenta-se diagnóstico situacional } \\
\text { da coleção e sugerem-se melhorias quanto à } \\
\text { preservação, conservação e divulgação da } \\
\text { mesma. }\end{array}$ \\
\hline $\begin{array}{l}\text { Ana Luiza de Sá } \\
\text { Magalhães. }\end{array}$ & $\begin{array}{l}\text { Prontuário médico do Hos- } \\
\text { pital Universitário: uma } \\
\text { política de arquivo, gestão } \\
\text { e gerenciamento. }\end{array}$ & $\begin{array}{l}\text { Análise da problemática referente ao fluxo do } \\
\text { prontuário médico nas dependências do hospi- } \\
\text { tal, chamando a atenção da comunidade interna } \\
\text { do hospital universitário da Universidade Fede- } \\
\text { ral do Maranhão, para a importância desse do- } \\
\text { cumento, como instrumento legal, e das infor- } \\
\text { mações clínicas nele registradas, necessárias }\end{array}$ \\
\hline
\end{tabular}




\begin{tabular}{|c|c|c|}
\hline & & $\begin{array}{l}\text { para viabilizar o desenvolvimento das atividades } \\
\text { e, como instrumento essencial para garantir o } \\
\text { exercício de cidadania do paciente. Enfatizam- } \\
\text { se os benefícios que a implantação dessa políti- } \\
\text { ca trará para o hospital. }\end{array}$ \\
\hline $\begin{array}{l}\text { Ana Maria Coe- } \\
\text { lho Ferreira; } \\
\text { Claudete Maria } \\
\text { Gonçalves } \\
\text { Brandão. }\end{array}$ & $\begin{array}{l}\text { O Acervo fotográfico do } \\
\text { Memorial Roseana Sarney. }\end{array}$ & $\begin{array}{l}\text { Resgate do histórico da fotografia, seus precur- } \\
\text { sores na busca pelo aperfeiçoamento das técni- } \\
\text { cas utilizadas e a introdução da imagem digital, } \\
\text { destacando-se suas vantagens e desvantagens } \\
\text { na conservação e preservação da informação. } \\
\text { Enfatiza-se a implantação do projeto de organi- } \\
\text { zação do acervo fotográfico adotado pelo Memo- } \\
\text { rial Roseana Sarney, evidenciando-se as meto- } \\
\text { dologias requeridas para a implantação do mes- } \\
\text { mo. }\end{array}$ \\
\hline $\begin{array}{l}\text { Carmencita Mar- } \\
\text { tins Santos; Ma- } \\
\text { rileide de Jesus } \\
\text { Moraes Araújo }\end{array}$ & $\begin{array}{l}\text { Análise do processo de } \\
\text { avaliação de documentos } \\
\text { dos arquivos: Banco do } \\
\text { Estado do Maranhão } \\
\text { (BEM), Companhia Ener- } \\
\text { gética do Maranhão } \\
\text { (CEMAR) Empresa Brasi- } \\
\text { leira de Correios e Telé- } \\
\text { grafos (ECT) e Centrais } \\
\text { Elétricas do Norte do Brasil } \\
\text { (ELETRONORTE). }\end{array}$ & $\begin{array}{l}\text { Abordagem do processo avaliativo dos docu- } \\
\text { mentos de arquivo, abrangendo a formação da } \\
\text { comissão de avaliação, a análise da produção } \\
\text { documental com ênfase no valor e termo de des- } \\
\text { tinação dos documentos como também a tabela } \\
\text { de temporalidade. Destacam-se as empresas: } \\
\text { Banco do Estado do Maranhão (BEM), Compa- } \\
\text { nhia Energética do Maranhão (CEMAR), Empre- } \\
\text { sa Brasileira de Correios e Telégrafos (Correios) } \\
\text { e Centrais Elétricas do Norte do Brasil } \\
\text { (ELETRONORTE). }\end{array}$ \\
\hline $\begin{array}{l}\text { Claudia Maria P. } \\
\text { de Abreu Pece- } \\
\text { gueiro; Raimun- } \\
\text { da Nonata Araú- } \\
\text { jo Teixeira. }\end{array}$ & $\begin{array}{l}\text { Programa de gestão do- } \\
\text { cumental na Justiça do } \\
\text { Trabalho do Maranhão: um } \\
\text { relato de experiência junto } \\
\text { ao Arquivo do TRT da } 16^{a} \\
\text { Região e varas do traba- } \\
\text { lho. }\end{array}$ & $\begin{array}{l}\text { Relato do programa de gestão documental na } \\
\text { Justiça do Trabalho do Maranhão. Na aborda- } \\
\text { gem, as autoras fazem considerações sobre a } \\
\text { teoria arquivística à luz de alguns estudiosos. } \\
\text { Descrevem-se os arquivos jurídicos, relacionan- } \\
\text { do-os às espécies documentais mais comuns da } \\
\text { área. Sugere-se como conclusão dos estudos a } \\
\text { continuidade do trabalho com o estabelecimento } \\
\text { de uma sistemática, integrada e eficiente voltada } \\
\text { à preservação e conservação do acervo docu- } \\
\text { mental e a sua imediata recuperação. }\end{array}$ \\
\hline $\begin{array}{l}\text { Clores Holanda } \\
\text { Silva; Rosenilde } \\
\text { Galdez Costa. }\end{array}$ & $\begin{array}{l}\text { Estudo dos documentos } \\
\text { arquivísticos das igrejas } \\
\text { católicas do centro de São } \\
\text { Luis. }\end{array}$ & $\begin{array}{l}\text { Discussão sobre os acervos de instituições reli- } \\
\text { giosas de São Luis, tombadas pelo Instituto do } \\
\text { Patrimônio Histórico, Artístico e Nacional - } \\
\text { IPHAN. A pesquisa objetivou conhecer a realida- } \\
\text { de desses arquivos sociais e/ou religiosos no } \\
\text { que se refere aos acervos, usuários, estrutura } \\
\text { física, meio ambiente, suporte, acondicionamen- } \\
\text { to, reprodução, conservação, políticas de avali- } \\
\text { ação e gestão documental. Tais resultados de- } \\
\text { ram elementos para a elaboração de um diag- } \\
\text { nóstico sobre os documentos arquivísticos des- } \\
\text { sas igrejas, ainda aquém dos padrões exigidos } \\
\text { pela arquivística contemporânea. }\end{array}$ \\
\hline $\begin{array}{l}\text { Edilene Ribeiro } \\
\text { Campos; Maria } \\
\text { do Carmo Mar- } \\
\text { tins de Souza. }\end{array}$ & $\begin{array}{l}\text { A realidade do arquivo dos } \\
\text { cemitérios da rede pública } \\
\text { municipal de São Luis. }\end{array}$ & $\begin{array}{l}\text { Estudo sobre o Arquivo dos Cemitérios Públicos } \\
\text { do Município de São Luis. A pesquisa objetivou } \\
\text { diagnosticar as condições físicas e de organiza- } \\
\text { ção do acervo documental. Os sujeitos da pes- }\end{array}$ \\
\hline
\end{tabular}




\begin{tabular}{|c|c|c|}
\hline & & $\begin{array}{l}\text { quisa foram a administração da Centurion e a } \\
\text { equipe envolvida nos trabalhos do arquivo. Apre- } \\
\text { senta-se, ainda, o arranjo dos documentos, iden- } \\
\text { tificando-se os métodos de arquivamento, bem } \\
\text { como a forma de recuperação e as condições de } \\
\text { acesso e uso que o arquivo adota em função da } \\
\text { conservação e preservação do conjunto docu- } \\
\text { mental. }\end{array}$ \\
\hline $\begin{array}{l}\text { Elcinete de Je- } \\
\text { sus Coutinho }\end{array}$ & $\begin{array}{l}\text { Ações empreendedoras no } \\
\text { campo da arquivística no } \\
\text { Maranhão: relato de expe- } \\
\text { riência. }\end{array}$ & $\begin{array}{l}\text { Discussão acerca das atitudes empreendedoras } \\
\text { em prestação de serviços na área Arquivística do } \\
\text { Estado do Maranhão. Apresentam-se aspectos } \\
\text { primordiais para a formalização e criação de em- } \\
\text { presas, a importância de se planejarem os negó- } \\
\text { cios neste campo da informação como fator rele- } \\
\text { vante no desenvolvimento empresarial e das } \\
\text { atividades no que tange à administração docu- } \\
\text { mental. }\end{array}$ \\
\hline $\begin{array}{lr}\text { Elizabete } & \text { Pitman } \\
\text { Berniz; Marcio } \\
\text { Henrique de } \\
\text { Jesus Almeida. }\end{array}$ & $\begin{array}{l}\text { O perfil do profissional } \\
\text { arquivista na sociedade da } \\
\text { informação. }\end{array}$ & $\begin{array}{l}\text { Análise do perfil dos profissionais que atuam em } \\
\text { arquivos em São Luís, com vistas a compreen- } \\
\text { der as suas práticas, suas formas de atualização } \\
\text { e como o Curso de Especialização em Gestão } \\
\text { de Arquivos pode potencializar tais práticas, com } \\
\text { base num referencial teórico-metodológico con- } \\
\text { sistente e atualizado. }\end{array}$ \\
\hline $\begin{array}{l}\text { Francisca The- } \\
\text { reza Coelho de } \\
\text { Andrade }\end{array}$ & $\begin{array}{l}\text { São Luis patrimônio da } \\
\text { humanidade: contribuição } \\
\text { do Arquivo Público do Es- } \\
\text { tado do Maranhão para o } \\
\text { turismo cultural. }\end{array}$ & $\begin{array}{l}\text { Estudo avaliativo das possibilidades de inserção } \\
\text { de arquivos públicos no turismo cultural. Bus- } \\
\text { cam-se respostas à problemática sobre patrimô- } \\
\text { nio cultural, documental, histórico, turístico, re- } \\
\text { correndo à pesquisa documental na perspectiva } \\
\text { de avaliar a possibilidade de sua inserção no } \\
\text { turismo cultural fundamentado na necessidade } \\
\text { de preservação da memória documental da insti- } \\
\text { tuição. }\end{array}$ \\
\hline $\begin{array}{l}\text { Geysa Andrea } \\
\text { Soares Carvalho } \\
\text { Pereira; Sylvana } \\
\text { Cavalcante de } \\
\text { Sá. }\end{array}$ & $\begin{array}{l}\text { Arquivo museológico: o } \\
\text { caso do Museu Histórico e } \\
\text { Artístico do Maranhão. }\end{array}$ & $\begin{array}{l}\text { Estudo sobre o acervo museológico do Museu } \\
\text { Histórico e Artístico do Maranhão - MHAN. A- } \\
\text { presentam-se os conceitos e antecedentes histó- } \\
\text { ricos de arquivos e museus. Discorre-se sobre a } \\
\text { história e arquitetura do referido museu e os } \\
\text { seus respectivos anexos: Cafua das Mercês, } \\
\text { Capela das Laranjeiras, Igreja do Desterro e Ca- } \\
\text { pela Bom Jesus dos Navegantes, apresentando- } \\
\text { se fotos dos acervos, organização, política de } \\
\text { aquisição de materiais, registro e processamento } \\
\text { técnico. }\end{array}$ \\
\hline $\begin{array}{l}\text { Ivesangela Lou- } \\
\text { reiro Ribeiro; } \\
\text { Maria Lúcia Soa- } \\
\text { res Fonseca }\end{array}$ & $\begin{array}{l}\text { A experiência do Curso de } \\
\text { Especialização em Gestão } \\
\text { de Arquivo na Universida- } \\
\text { de Federal do Maranhão. }\end{array}$ & $\begin{array}{l}\text { Discussão acerca da Arquivologia no Brasil co- } \\
\text { mo ciência, enfatizando a criação dos cursos de } \\
\text { graduação e pós-graduação, e apontando os } \\
\text { parâmetros legais para a criação e implantação } \\
\text { destes. Registra-se a implantação do Curso de } \\
\text { Especialização em Gestão de Arquivos e sua } \\
\text { importância no desenvolvimento dessa Ciência } \\
\text { no Maranhão. }\end{array}$ \\
\hline José de Ribamar & Arquivo do Tribunal de & Diagnóstico da situação atual do Arquivo do Tri- \\
\hline
\end{tabular}




\begin{tabular}{|c|c|c|}
\hline $\begin{array}{l}\text { Lopes Nojosa; } \\
\text { Valdelina Anto- } \\
\text { nia Frazão }\end{array}$ & $\begin{array}{l}\text { Contas do Estado do Ma- } \\
\text { ranhão: reflexos sobre a } \\
\text { gestão documental. }\end{array}$ & $\begin{array}{l}\text { bunal de Contas do Estado do Maranhão. Res- } \\
\text { salta-se a importância de tornar efetiva a gestão } \\
\text { de documentos nos órgãos públicos e, em espe- } \\
\text { cial, no tribunal de contas, com vistas à obtenção } \\
\text { de subsídios para a implantação futura de uma } \\
\text { política arquivística no órgão. }\end{array}$ \\
\hline $\begin{array}{l}\text { Lucia de Fátima } \\
\text { Moreira Serra } \\
\text { Silva; Rosana da } \\
\text { Silva Sousa. }\end{array}$ & $\begin{array}{l}\text { Memória e cidadania: por } \\
\text { uma política de preserva- } \\
\text { ção da documentação do } \\
\text { cartório da Comarca de } \\
\text { Viana dos séculos XVIII- } \\
\text { XX. }\end{array}$ & $\begin{array}{l}\text { Resgate da formação histórica do Município de } \\
\text { Viana, da organização judiciária e do histórico do } \\
\text { Tribunal de Justiça do Maranhão. Apresentam-se } \\
\text { as políticas e técnicas de conservação e preser- } \\
\text { vação de documentos, relacionando com os do- } \\
\text { cumentos do cartório da Comarca de Viana e a } \\
\text { aplicação de normas internacionais para arranjo } \\
\text { de acervos documentais. }\end{array}$ \\
\hline $\begin{array}{l}\text { Márcia Cristina } \\
\text { da Cruz Pereira; } \\
\text { Vitória Graça de } \\
\text { Carvalho. }\end{array}$ & $\begin{array}{l}\text { Arquivo fotográfico do Ins- } \\
\text { tituto do Patrimônio Histó- } \\
\text { rico e Artístico Nacional - } \\
\text { IPHAN: uma análise. }\end{array}$ & $\begin{array}{l}\text { Histórico da fotografia, destacando-se seu sur- } \\
\text { gimento no Brasil. Ressalta-se a importância da } \\
\text { fotografia como documento na preservação da } \\
\text { memória e os procedimentos técnicos arquivísti- } \\
\text { cos no tratamento da documentação fotográfica. } \\
\text { Aborda-se, ainda, a relação entre fotografia e } \\
\text { patrimônio histórico cultural tendo o arquivo foto- } \\
\text { gráfico do IPHAN como objeto de estudo. }\end{array}$ \\
\hline $\begin{array}{l}\text { Maria de Fátima } \\
\text { Oliveira Costa } \\
\text { Pinheiro; Ro- } \\
\text { sanna Maria } \\
\text { Costa Bezerra. }\end{array}$ & $\begin{array}{l}\text { Preservação e conserva- } \\
\text { ção preventiva: subsídios } \\
\text { para gestão do acervo de } \\
\text { livros da Biblioteca Central } \\
\text { da UFMA. }\end{array}$ & $\begin{array}{l}\text { Proposição para elaborar uma política de preser- } \\
\text { vação e conservação preventiva para o acervo } \\
\text { de livros, abordando as questões de espaço físi- } \\
\text { co, controle ambiental, iluminação, mobiliário, } \\
\text { acondicionamento, manuseio do acervo, higieni- } \\
\text { zação, segurança, prevenção de acidentes, prá- } \\
\text { ticas de reparos de livros, exposições, preserva- } \\
\text { ção defensiva e transferência de suportes da } \\
\text { informação, com ênfase para a microfilmagem e } \\
\text { a digitalização. }\end{array}$ \\
\hline $\begin{array}{l}\text { Maria Jose Nava } \\
\text { Castro; Tânia } \\
\text { Maria Araújo } \\
\text { Pavão. }\end{array}$ & $\begin{array}{l}\text { Arquivo Permanente da } \\
\text { Associação Comercial do } \\
\text { Maranhão (ACM): proposta } \\
\text { de organização. }\end{array}$ & $\begin{array}{l}\text { Proposta de reorganização do Arquivo Perma- } \\
\text { nente da Associação Comercial do Maranhão } \\
\text { (ACM). A metodologia adotada compreendeu } \\
\text { tanto uma pesquisa documental sobre a literatu- } \\
\text { ra disponível sobre o assunto e o levantamento e } \\
\text { análise dos dados sobre a instituição, o que pos- } \\
\text { sibilitou a elaboração de um diagnóstico. De } \\
\text { posse das informações, delineou-se a proposta } \\
\text { de organização do citado arquivo. Conclui-se } \\
\text { que com a nova organização as informações } \\
\text { custodiadas neste arquivo serão obtidas com } \\
\text { mais eficácia e rapidez, facilitando as tomadas } \\
\text { de decisão da Associação Comercial. }\end{array}$ \\
\hline $\begin{array}{l}\text { Maria de Lour- } \\
\text { des Rodrigues } \\
\text { Fernandes; An- } \\
\text { tonio Souza Sil- } \\
\text { va }\end{array}$ & $\begin{array}{l}\text { Reflexões sobre a infor- } \\
\text { mação significativa no } \\
\text { prontuário do paciente. }\end{array}$ & $\begin{array}{l}\text { Estudo que aponta através de uma evolução } \\
\text { histórica do registro médico, suas funções e ob- } \\
\text { jetivos, o valor da informação significativa dentro } \\
\text { do prontuário do paciente como base para pes- } \\
\text { quisa, melhorar os procedimentos clínicos nas } \\
\text { tomadas de decisões e proporcionar maior quali- } \\
\text { dade na administração do hospital de modo ge- } \\
\text { ral. Aborda ainda as definições do prontuário do } \\
\text { paciente, tanto em papel como eletrônico, e suas }\end{array}$ \\
\hline
\end{tabular}


A dimensão do Curso de Gestão de Arquivo... Maria M. Ferreira; Aldinar M. Bottentuit; Georgete L. Freitas

\begin{tabular}{|l|l|}
\hline & $\begin{array}{l}\text { vantagens e desvantagens no sentido de mostrar } \\
\text { como a informação significativa constitui-se em } \\
\text { elemento determinante na produção de um regis- } \\
\text { tro médico contextualizado dentro do prontuário } \\
\text { do paciente. }\end{array}$ \\
\hline
\end{tabular}

